\title{
Povezovanje matematike z okoljem skozi ustvarjalno reševanje avtentičnih problemov
}

\author{
Amalija Žakelj \\ Univerza na Primorskem \\ amalija.zakelj@pef.upr.si \\ Andreja Klančar \\ Univerza na Primorskem \\ andreja.klancar@pef.upr.si
}

\begin{abstract}
Ustvarjalnost je pomemben del našega vsakdana in hkrati pomemben dejavnik pri spodbujanju inovativnosti in oblikovanju novih idej, kar je ključnega pomena za posameznikov trajnostni razvoj. Kako se ta odraža, je odvisno od naše osebnosti, temperamenta, močnih področij in okolja, v katerem živimo in delujemo. Številni avtorji so si edini, da je ustvarjalno razmišljanje tisto razmišljanje, ki privede do novih spoznanj, novih pristopov, nove perspektive, novega načina razumevanja stvari, ter to vrsto razmišljanja izpostavljajo kot dinamičen miselni proces, ki vključuje divergentno in konvergentno razmišljanje. $\mathrm{V}$ prispevku posebej predstavimo merila in pogoje, ki so potrebni za ustvarjalnost pri matematiki, povezavo matematike z okoljem, kjer na primerih avtentičnih problemov razčlenimo štiri komponente ustvarjalnega mišljenja: fluentnost, fleksibilnost, izvirnost in elaboracijo. Skozi reševanje realističnih in matematičnih problemov razdelamo poti ustvarjalnega razmišljanja, med drugim pri reševanju odprtih problemov, algoritemskem reševanju problemov, oblikovanju izvirnih vprašanj idr. Pri reševanju izbranih primerov nakažemo možnosti povezovanja in stopnjevanja zahtevnosti po vertikali od osnovne do srednje šole.
\end{abstract}

Ključne besede: ustvarjalnost, inovativnost, matematika, avtentični problemi, ustvarjalno mišljenje

\section{Uvod}

Svet, ki ga poznamo, se hitro spreminja. Nabor spretnosti, ki jih imamo zdaj, verjetno že čez nekaj let ne bo več zadostoval oz. se bodo pojavile zahteve po novih znanjih, spretnostih, ki jih danes še ne poznamo ali pa jih le slutimo. Sposobnost prilagajanja novim razmeram in situacijam postaja ključna spretnost, ustvarjalnost pa vse bolj cenjena. Vedno pogosteje si zastavljamo vprašanje, kako lahko pripravimo svoje otroke na to hitro spreminjajoče se 
okolje. De Corte (2010) ter Rutar Ilčeva in Pavlič Škerjančeva (2010) so že leta 2010 opozorili na t. i. transverzalne veščine, pomembne za življenje in delo v 21. stoletju, kot npr.: reševanje težav, timsko delo in sodelovanje, ustvarjalnost in inovativnost, digitalna kompetenca, kritično razmišljanje, učenje učenja idr. De Corte $(2010,45)$ je izpostavil, da je »končni cilj učenja in poučevanja izgradnja sprilagodljive kompetences, to je zmožnosti, da naučeno in osmišljeno znanje in razvite veščine uporabljamo v različnih situacijah na prožen in ustvarjalen način«.

Raziskave o ustvarjalnosti (Sriraman in Haavold 2017) so temeljne v svetu hitrih inovacij, izumov, rešitev in sintez, zato ne preseneča, da za ustvarjalnost $v$ zadnjem obdobju med raziskovalci obstaja veliko zanimanja (Akgul in Kaveci 2016). Pri razpravah o ustvarjalnosti pogosto zasledimo stališče, da so osebe bodisi ustvarjalne ( $z$ domišljijo, odprtih pogledov) ali pa ne (logične, ozkih pogledov, toge $v$ razmišljanju). Kirby (2003) v povezavi z ustvarjalnostjo osebe deli na bolj ali manj ustvarjalne, De Bono (2009) pa nas pouči, da se lahko naučimo biti ustvarjalni.

Ustvarjalne osebe dosegajo nadpovprečne rezultate (Glogovec in Žagar 1992), vendar pa se je potrebno zavedati, da inteligentnost sama po sebi ne pomeni ustvarjalnosti. Pečjak (1987) poudarja, da je za ustvarjalnost potrebno usklajevanje divergentnega in konvergentnega mišljenja, ki ima ključno vlogo pri vrednotenju ustvarjalnega dosežka; izpostavlja izrazito korelacijo med ustvarjalnostjo in humorjem ter duhovitimi odgovori. Jurčová (2005) izpostavlja, da so visoko ustvarjalni ljudje socialno kompetentnejši. Pogumnejši so v izražanju, imajo visoke neverbalne socialne sposobnosti in zato bolj raznolike socialne interakcije. Marentič Požarnikova (2003) pa ustvarjalne ljudi opiše kot radovedne ljudi, ki jih izzovejo novosti predmeta ali pojava, presenečenje, sprememba, nesmiselnost, neskladje, kompleksnost, negotovost, medtem ko monotonija njihovo radovednost »ubija«. Ustvarjalni ljudje se vzdržujejo prenagljenih sodb, nimajo potrebe po obrambi, ker ne dojemajo izkušenj kot ogrožajočih. Odlikujejo jih miselna neodvisnost in odprtost za nove izkušnje.

Marentič Požarnikova (2003) opozarja, da šolski sistem daje večjo prednost analitičnosti, logičnosti, linearnemu zaporedju itd., premalo pa ustvarjalnosti, slikovnosti, čustvenosti, celostnemu dojemanju, intuiciji itd. Podobno navajajo tudi Baranova, Erdoganova in Çakmakova (2011), ki pravijo, da bi moralo biti razvijanje ustvarjalnih talentov visoko na seznamu prednostnih nalog izobraževanja, tako pri posameznih disciplinah kot tudi interdisciplinarno. Boalerjeva in Dweckova (2016) ter Silver (1997) dodajajo, da ustvarjalnost ni le za nadarjene učence, temveč je primerna za splošno šolsko popu- 
lacijo, zato je cilje za razvoj osebnostnih lastnosti, ki so potrebne za ustvarjalnost, ter cilje, ki spodbujajo ustvarjalnost pri učencih, potrebno vključiti v šolske kurikule.

Ustvarjalna disciplina je tudi matematika. V nas spodbuja občutek veselja in zadovoljstva, ko prvič samostojno in sami rešimo problem. Za večino ljudi cilj učenja matematike ni, da bi postali specialisti v matematiki, temveč da bi se zanjo zanimali ter cenili njeno širino in lepoto. Matematika je estetska, ustvarjalna in se v naravi pojavlja v čudovitih situacijah.

Usmeritve za spodbujanje ustvarjalnosti pri učencih najdemo tudi $v$ učnem načrtu za matematiko za osnovno šolo po vsej vertikali, od prvega do tretjega triletja. Tako je že v opredelitvi predmeta med drugim zapisano, da pri pouku matematike spodbujamo različne oblike mišljenja in ustvarjalnosti ter da je potrebno učence usposobiti za uporabo in povezovanje znanja ter razvijanje ustvarjalnosti. Zmožnost prenosljivosti znanja oblikuje suverenejšo osebnost, ki se lahko sooča z različnimi izzivi, hkrati pa zmožnost povezovanja različnih znanj in spretnosti prispeva $k$ večji kulturni in etični zavesti posameznika (Ministrstvo za šolstvo in šport 2011).

Še konkretneje je ustvarjalnost opredeljena $v$ globalnih oz. splošnih ciljih predmeta, kjer med drugim lahko preberemo, da učenci »spoznavajo matematiko kot proces ter se učijo ustvarjalnosti in natančnosti« (Ministrstvo za šolstvo in šport 2011, 5), v operativnih ciljih posameznih triletij pa, da »učenci razvijajo ustvarjalnost ob reševanju besedilnih nalog z več rešitvami in pri iskanju ter uporabi različnih poti do rešitev« (str. 37); »razvijajo ustvarjalnost in samoiniciativnost « (str. 57); v didaktičnih priporočilih sklopa Matematični problemi in problemi z življenjskimi situacijami pa priporočila, »da učenci s samostojnim oblikovanjem različnih vzorcev razvijajo ustvarjalnost“ (str. 62). V okviru standardov znanja najdemo zapise, ki so povezani z ustvarjalnostjo, in sicer: »Pričakujemo, da bo učenec pri pouku matematike, v času izobraževanja in po končani osnovni šoli obvladal splošna (temeljna) matematična znanja in spretnosti, ki so potrebna za ustvarjalnost in uporabo« (str. 64).

Poleg ciljev in standardov znanj so $v$ učnem načrtu za matematiko tudi priporočila za dejavnosti za razvoj ustvarjalnosti: opazovanje, nadaljevanje, izdelovanje vzorca; v povezavi z likovno vzgojo, s tehniko in tehnologijo izdelati izrazno preiskavo (npr. predstaviti simetrijo v naravi, zlati rez, slikovna zaporedja z geometrijskimi vzorci idr.) (Ministrstvo za šolstvo in šport 2011).

\section{Opredelitev ustvarjalnosti}

Številni avtorji (McGregor 2007; Chamberlin in Mann 2014; Imai 2010; Kim, Cho in Ahn 2003; Leikin in Lev 2007; Siswono 2011; Sriraman 2004; Sriraman in Haa- 
vold 2017) navajajo, da je ustvarjalno razmišljanje tisto razmišljanje, ki privede do novih spoznanj, novih pristopov, nove perspektive in novega načina razumevanja stvari, ter izpostavljajo štiri pogoje, ki so potrebni za ustvarjalnost:

- fluentnost: sposobnost odkrivanja velikega števila idej,

- fleksibilnost: sposobnost odkrivanja različnih idej,

- izvirnost: sposobnost odkrivanja novih idej,

- elaboracija: sposobnost natančne izdelave ideje in njenega posredovanja drugim.

Munandar (2002) fluentnost opisuje kot miselne veščine, ki lahko sprožijo številne ideje, rešitve problema, domisleke številnih primerov, ki so povezani s konceptom $v$ določenih situacijah. Fluentnost je pogosto opredeljena s kvantitativnim vidikom. Pravimo, da posameznik demonstrira fluentnost, če je sposoben $v$ kratkem času zasnovati več rešitev, poiskati različne poti reševanja, četudi niso vse zares nove in originalne. Petačeva (2011) navaja besedno fluentnost kot sposobnost lahkotnega produciranja besed $v$ slovenskem jeziku. Fluentnost izražanja spodbujamo $z$ vajami, pri katerih učenci dopolnjujejo besede (pesmi, zgodbe) z izbranimi besedami in s številnimi vajami za bogatitev besedišča ter povezujejo besede v smiselne povedi (Petač 2011). Dejavnosti, ki spodbujajo fluentnost pri matematiki, so lahko navajanje primerov (primera 2 in 3 ) ali izjav, povezanih z določenimi pojmi ali situacijami, ali pa k danim primerom dodajamo nove primere ali protiprimere, razlagamo pojme s svojimi besedami, iščemo sopomenke idr.

Primer 1: Naštevanje čim večjega števila besed, ki vsebujejo »roka«.

Fluentni odgovori: brezrokavnik, rokavica, poroka

Primer 2: Zapiši številski izraz, katerega vrednost je enaka 20.

Fluentni odgovori: $10+10 ; 12+8 ; 4 \cdot 5 ; 2 \frac{20}{2^{2}}+\left(10^{-1}\right)^{-1} ; 10^{20} ; 2^{4}+2^{2}$.

Rešitve danega primera dopuščajo divergentnost $v$ odgovorih in so, kot vidimo, povezane $z$ različnimi matematičnimi vsebinami in pojmi (različne računske operacije, potence $z$ naravnim in celim eksponentom, logaritem). Prve tri odgovore lahko ustvarijo že učenci prve triade osnovne šole, izraze s potencami pa učenci višjih razredov osnovne šole, medtem ko lahko izraz $z$ logaritmom pričakujemo šele $v$ srednji šoli. Vsekakor pa se na izziv lahko odzovejo vsi učenci, ne glede na razred. Od znanja in njihove ustvarjalnosti bo odvisno, katere rešitve bodo predlagali.

Pavlič Škerjančeva (2013) za razvijanje besedišča pri različnih predmetih predlaga uporabo Frayerjevega modela. To je učna aktivnost, ki temelji na ka- 
Preglednica 1 Frayerjev model za krožnico

\begin{tabular}{l} 
Definicija (primeri zapisov učencev z lastnimi besedami) \\
Krožnica je množica točk v ravnini, ki so od skupne točke (središča) enako oddaljene. \\
Krožnica je sklenjena kriva črta, ki jo sestavljajo točke, ki so od skupne točke (središča) enako \\
oddaljene. \\
Možica točk, ki so od skupne točke (središča) enako oddaljne. \\
\hline Značilnosti \\
Vsaka točka je od izbrane točke (središča) oddaljena natanko polmer. \\
Krožnico sestavlja neskončno mnogo točk. \\
Je sklenjena kriva črta. \\
\hline Primeri: obroba okroglega prta, obroč, obod ure. \\
\hline Protiprimer: krog.
\end{tabular}

tegorizaciji besed, namenjena razvijanju/poglabljanju razumevanja pojmov. Učenci analizirajo bistvene in nebistvene lastnosti besed/pojmov, tako da navajajo primere in protiprimere ter pojem razložijo s svojimi besedami.

Primer 3: Frayerjev model za krožnico. Pri matematiki za izbrani pojem, npr. krožnica (preglednica 1), učenci najprej opredelijo definicijo krožnice, nato zapisujejo njene značilnosti ter navajajo primere in protiprimere. Razmišljanje o krožnici na tak način dopušča divergentnost, z navajanjem raznolikih primerov, protiprimerov in lastnih opisov pa tudi originalnost in fluentnost. Tovrstna aktivnost poglablja tudi razumevanje pojmov in bogati besedišče.

Munandar (2002), Mann (2005) ter Leikinova in Levova (2007) fleksibilnost opisujejo kot spretnost prožnega razmišljanja, ki vključuje sposobnost ustvarjanja raznolikih idej in raznolikih rešitev problema ter sposobnost lahkotnega menjavanja strategij v mišljenju (Pogačnik 1995, 171). Fleksibilnost v mišljenju pomeni, da je človek sposoben na stvari pogledati z različnih zornih kotov ter da spremeni miselne poti in načine reševanja problema, kadar naleti na slepo ulico ali miselno oviro (Krutetskii 1976; Leikin in Lev 2007). Posameznik, ki izkazuje visoko stopnjo prilagodljivosti, bo zamenjal miselne poti oz. pristope reševanja, če ti niso učinkoviti in ne vodijo do rešitve. Za spodbujanje fleksibilnosti pri učencih izbiramo vaje, pri katerih se odzivajo samoiniciativno (primer 4).

Primer 4: Dano daljico razdeli na 2, 4 in 5 enako dolgih delov.

Učenci bodo pokazali fleksibilnost, ko pri delitvi daljice na pet enako dolgih delov ne bodo vztrajali z razpolavljanjem, ko bodo ugotovili, da ta način delitve na pet enako dolgih delov ni mogoč, temveč bodo začeli razmišljati o primernejši strategiji reševanja (npr. uporabili bodo Talesov izrek). 
Merilo ustvarjalnosti je tudi izvirnost. Izvirno razmišljanje vključuje miselne sposobnosti (novost), ki rojevajo nove ideje, izvirne poti reševanja, edinstvene rešitve, nove izraze, neobičajno razmišljanje in neobičajno izražanje (Munandar 2002).

Zadnji in zelo pomemben kazalnik ustvarjalnosti je elaboracija - sposobnost posameznika, da natančno razdela idejo, jo realizira (npr. v obliki izdelka) in jo posreduje drugim (Imai 2010).

\section{Pristopi poučevanja za spodbujanje ustvarjalnosti}

Ustvarjalnost je za družbo pomembna, saj brez nje ne bi bilo ustvarjalnih rešitev (Woolfolk 2002, 121), zato se je smiselno vprašati, kako jo podpirati in razvijati pri pouku $v$ šoli, katere so tiste učne metode, ki spodbujajo razvoj ustvarjalnosti učencev.

V pedagoški literaturi se razpravlja o različnih skupinah učnih metod verbalnih, dokumentacijskih, demonstracijskih, operacijsko-praktičnih (Valenčič Zuljan in Kalin 2020), učnih metodah za aktivno posredovanje učnih vsebin, metodah za aktivno učenje, metodah za spodbujanje komunikacije (Brečko 2002) - in o različnih didaktičnih strategijah, kot so npr. odkrivajoči pouk, raziskovalni pouk, projektni pouk, problemski pouk, ravnanjsko ali delovno usmerjeni pouk, izkustveni pouk, pouk s pomočjo sodobnih tehnologij idr. (Strmčnik 2003), redkeje pa o ustvarjalnih učnih metodah ali o učnih metodah, ki spodbujajo tudi ustvarjalnost učencev.

Petačeva (2011) pri slovenščini navaja metode za razvijanje ustvarjalnosti pri pouku slovenščine, kot so npr. metoda pogovora, diskusije; monološka metoda oz. metoda samostojnega pisanja, ustvarjanja, pripovedovanja; metoda poročanja; metoda dela z besedilom (tiho branje, glasno interpretativno branje in analiziranje besedila); metoda pisnih izdelkov (pisanje ustvarjalnih in polustvarjalnih besedil); metoda vodenja, pri kateri ima učitelj vlogo spodbujevalca oz. mentorja svojim učencem. Med metode za razvijanje ustvarjalnosti prištevamo tudi ustvarjalne igre, analizo SWOT, Vennov diagram, metodo šest klobukov, ribjo kost ter vaje za razvijanje fluentnosti idej.

Ruseffendi (2006) dodaja, da naj učenci za razvoj ustvarjalnosti raziskujejo učno gradivo, iščejo lastne načine reševanja problema, aktivno sodelujejo $v$ razpravah in diskusijah idr. Tudi medpredmetno povezovanje, izdelovanje in uporaba didaktičnih pripomočkov, reševanje matematičnih in realističnih problemov idr. so priložnosti za ustvarjalno učenje in poučevanje.

$S$ primernimi prilagoditvami so predlagane metode in dejavnosti uporabne tudi pri matematiki, npr. $v$ obliki: branja z refleksijo, razvijanja besedišča, interpretiranja matematičnih dejstev in konceptov, izdelave matema- 
tičnega slovarčka, interpretativnega branja. Za pridobivanje izkušenj z interpretiranjem matematičnih besedil je lahko učinkovito tudi branje kratkih zahtevnih besedil, pri katerih učenci interpretirajo besedilo $z$ vidika matematike (besedno in/ali na slikovni/grafični ravni).

Med takšna besedila lahko spadajo definicije in preprosti izreki v matematiki, ki naj jih učenci ne bi znali na pamet, ampak bi jih na inovativen način ilustrirali s sliko/skico ter jih razložili s svojimi besedami. Npr. trditev »Presečišče simetral katerih koli dveh nevzporednih tetiv kroga je središče kroga.» lahko predstavijo s sliko/grafično in zraven glasno interpretirajo/razlagajo situacijo.

\section{Reševanje realističnih in matematičnih problemov - poti ustvarjalnega razmišljanja}

Siswono (2008) predlaga merila za naloge, ki bi jih lahko uporabljali za spodbujanje razvoja ustvarjalnega mišljenja: izzivi naj bodo res problemske situacije in ne tipične naloge iz učbenika; problemi naj dopuščajo divergentnost v odgovorih in tudi načinih reševanja, tako da sledijo ciljem fleksibilnosti, originalnosti in fluentnosti; strategije, ki ne dajo popolne rešitve, lahko uporabimo kot iztočnico za razpravo; tudi različne poti do popolne rešitve ne smejo izostati; za učence, ki naloge niso razumeli, je lahko sošolčeva razlaga njegove lastne poti reševanja ustreznejša kot učiteljeva.

Ustvarjalno razmišljanje pri matematiki spodbujamo z različnimi tipi nalog: odprtimi matematičnimi in realističnimi problemi, oblikovanji problemov, nalogami razčlenjevanja (naloge algoritemskega razmišljanja), navajanji primerov in protiprimerov idr.

\section{Reševanje odprtih problemov}

Raziskovalci Barwell (2011) ter Hoffmanova in Brahier (2008) za razvoj ustvarjalnega mišljenja svetujejo reševanje odprtih problemov. Pri odprtih problemih je problemska situacija postavljena kot izziv, pri katerem vprašanja niso jasno postavljena. Za postavitev smiselnega vprašanja so potrebni uvid $v$ problemsko situacijo, razumevanje problema, specifično (matematično) znanje ter tudi druge spretnosti in veščine, potrebne za reševanje problemov. Učenci z vrsto in zahtevnostjo postavljenega vprašanja izkazujejo interes, motivacijo pa tudi raven znanja o obravnavani temi.

Reševanje odprtih problemov tako dopušča ustvarjanje in reševanje lastnih težav ter divergentnost v razmišljanju: navajanje različnih vprašanj odraža fluentnost, nova vprašanja izvirnost, smiselno prilagajanje poti reševanja in sposobnost posameznika, da v danem kontekstu izbira med najprimer- 


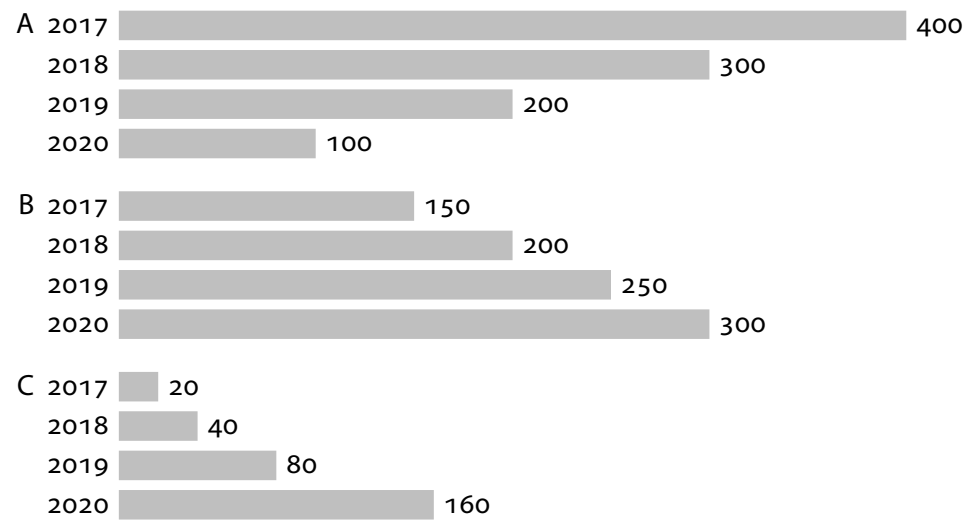

Slika 1 Grafični prikaz

nejšimi strategijami, kaže na fleksibilnost. Posledica inovativnih vprašanj in strategij reševanja so originalne rešitve.

Primer 5: Na sliki 1 prikaz ponazarja količino izdelkov A, B in C, ki jih proizvaja podjetje NoVo. Glede na dani prikaz zapišite različna vprašanja in problem rešite (prirejeno po Maharani 2014).

Problem je odprt, kar pomeni, da so vprašanja, ki si jih zastavi učenec, odvisna od njegovih znanja, interesa, motivacije, zanimanja idr. V nadaljevanju predstavljamo primere vprašanj, ki se stopnjujejo po vsebini, zahtevnosti in znanju, od osnovne do srednje šole.

1. Glede na podatke v prikazu za izdelke $A$ in $B$ določite:

a) Za koliko je število izdelkov v izbranem letu večje/manjše od števila $v$ predhodnem letu?

b) Kolikšen delež števila izdelkov predhodnega leta predstavlja število izdelkov izbranega leta?

2. Glede na podatke v prikazu za izdelke $A, B$ in $C$ določite:

a) Deleže števila proizvedenih izdelkov $v$ izbranem letu glede na število proizvedenih izdelkov v letu 2017. Kako se spreminja število proizvedenih izdelkov A, B in C skozi leta?

b) Deleže števila proizvedenih izdelkov $v$ izbranem letu glede na število proizvedenih izdelkov $v$ predhodnem letu.

3. V primeru, da bi se proizvodnja v podjetju NoVo spreminjala v enakem trendu tudi v naslednjih letih, določite prilagoditveni funkciji za izdelke $B$ in $C$. 
Preglednica 2 Deleži števila proizvedenih izdelkov v izbranem letu glede na število proizvedenih izdelkov v letu 2017

\begin{tabular}{|c|c|c|c|c|c|c|}
\hline \multirow[t]{2}{*}{ Leto } & \multicolumn{2}{|c|}{ Izdelek A } & \multicolumn{2}{|c|}{ Izdelek B } & \multicolumn{2}{|c|}{ Izdelek C } \\
\hline & $n$ & $k$ & $n$ & $k$ & $n$ & $k$ \\
\hline 2017 & 400 & 1 & 150 & 1 & 20 & 1 \\
\hline 2018 & 300 & $3 / 4$ & 200 & $4 / 3$ & 40 & 2 \\
\hline 2019 & 200 & $2 / 4$ & 250 & $5 / 3$ & 80 & 4 \\
\hline 2020 & 100 & $1 / 4$ & 300 & $6 / 3$ & 160 & 8 \\
\hline 2021 & 0 & $0 / 4$ & 350 & $7 / 3$ & 320 & 16 \\
\hline
\end{tabular}

Opombe $n$-število izdelkov, $k$-delež glede na leto 2017.

Ker je problem odprt, lahko primerno zahtevna vprašanja postavijo tako učenci na razredni kot predmetni stopnji osnovne šole ter $v$ srednji šoli. Tudi vprašanja, ki jih predlagamo zgoraj, se stopnjujejo po zahtevnosti. V nadaljevanju prikazujemo možne načine reševanja, glede na raven zahtevnosti, za izbrani dve vprašanji.

Glede na podatke v prikazu za izdelke A, B in C določite deleže števila proizvedenih izdelkov v izbranem letu glede na število proizvedenih izdelkov v letu 2017. Kako se spreminja število proizvedenih izdelkov A, B in C skozi leta?

Primer reševanja za osnovno šolo (preglednica 2). Možna interpretacija oz. odgovor učenca na raziskovalno vprašanje: opazovanje podatkov za izdelek A pokaže, da se število izdelkov iz leta v leto manjša, vsako leto enako, in sicer za 100 izdelkov. S tem se manjšajo tudi deleži proizvedenih izdelkov glede na leto 2017 in že v letu 2021 dosežejo vrednost o (nič). V nasprotju z izdelkom A se število izdelkov $B$ iz leta $v$ leto veča, vsako leto enako, in sicer za 50 izdelkov. Prav tako se iz leta $v$ leto večajo deleži proizvedenih izdelkov glede na začetno leto 2017, in sicer vsako leto za $1 / 3$ števila izdelkov v letu 2017. Število izdelkov $A$ iz leta v leto enakomerno pada, število izdelkov B iz leta v leto enakomerno raste, kar lahko učenec $v$ osnovni šoli poveže $s$ premim sorazmerjem. Drugače pa se iz leta v leto spreminja število izdelkov $C$. Le-to zelo hitro narašča, in sicer se število izdelkov iz leta v leto podvoji glede na prejšnje leto, tako da npr. že $v$ tretjem letu beležimo osemkratnik izdelkov glede na prvo leto 2017.

Primer reševanja za srednjo šolo (preglednica 3). Dijaki v srednji šoli lahko podatke zapišejo z uporabo simbolnega jezika, s spremenljivkami. Njihova interpretacija bi bila podobna kot pri učencih osnovne šole. Poleg opisov sprememb bi interpretacijo podatkov lahko nadgradili s poznavanjem odvisnosti 
Preglednica 3 Deleži števila proizvodov v izbranih letih glede na število proizvedenih izdelkov v prvem letu 2017

\begin{tabular}{|c|c|c|c|c|c|c|c|}
\hline \multirow[t]{2}{*}{ Leto } & \multirow[t]{2}{*}{ Št. leta } & \multicolumn{2}{|c|}{ Izdelek A } & \multicolumn{2}{|c|}{ Izdelek B } & \multicolumn{2}{|c|}{ Izdelek C } \\
\hline & & & $a_{i}=k \cdot a_{\mathrm{o}}$ & & $b_{i}=k \cdot b_{0}$ & & $c_{i}=k \cdot c_{0}$ \\
\hline 2017 & & $a_{\mathrm{o}}=400$ & & $b_{0}=150$ & & $c_{0}=20$ & \\
\hline 2018 & 1. & $a_{1}=300$ & $a_{1}=\frac{3}{4} a_{0}$ & $b_{1}=200$ & $b_{1}=\frac{4}{3} b_{0}$ & $c_{1}=40$ & $2 \cdot c_{0}$ \\
\hline 2019 & 2. & $a_{2}=200$ & $a_{1}=\frac{2}{4} a_{0}$ & $b_{2}=250$ & $b_{1}=\frac{5}{3} b_{0}$ & $c_{2}=80$ & $2^{2} \cdot c_{0}$ \\
\hline 2020 & 3. & $a_{3}=100$ & $a_{1}=\frac{1}{4} a_{0}$ & $b_{3}=300$ & $b_{1}=\frac{6}{3} b_{0}$ & $c_{3}=160$ & $2^{3} \cdot c_{0}$ \\
\hline 2021 & 4. & $a_{4}=0$ & $a_{1}=\frac{o}{4} a_{0}$ & $b_{4}=350$ & $b_{1}=\frac{7}{3} b_{0}$ & $c_{4}=320$ & $2^{4} \cdot c_{0}$ \\
\hline & $\ldots$ & & $\ldots$ & & $\ldots$ & & $\ldots$ \\
\hline & $n$ & & $\begin{array}{l}a_{n}=0 \\
n \geq 4\end{array}$ & & $b_{n}=\frac{n+3}{3} b_{0}$ & & $2^{n} \cdot c_{0}$ \\
\hline
\end{tabular}

Opombe $a_{i}$ - število izdelkov A v izbranem letu $(i=0,1,2, \ldots, n) ; b_{i}$ - število izdelkov $\mathrm{B} v$ izbranem letu $(i=0,1,2, \ldots, n) ; c_{i}$ - število izdelkov $C$ v izbranem letu $(i=0,1,2, \ldots, n) ; k$ - faktor spremembe.

količin, npr.: Iz opazovanih podatkov A in B prepoznamo premo sorazmerno spreminjanje, pri C eksponentno rast.

V primeru, da bi se proizvodnja spreminjala v enakem trendu, kot kažejo podatki $v$ prikazu, določite prilagoditveni funkciji za izdelka B in $C$.

Primer je primeren za srednjo šolo. Predpostavimo, da je leto 2017 začetno leto.

Izdelek B. Prilagoditvena funkcija: $V$ začetnem letu 2017 je število proizvodov 150. Podatki kažejo, da se proizvodnja vsako leto poveča za 50 izdelkov, kar pomeni, da točke ležijo na grafu linearne funkcije $y=50 x+150$.

Izdelek C. Prilagoditvena funkcija: Iz podatkov razberemo, da se proizvodnja vsako leto podvoji, kar pomeni, da točke ležijo na grafu eksponentne funkcije $y=20 \cdot 2^{x}$.

Matematična modela nakazujeta, da proizvodnja v obeh primerih narašča v nedogled, pri izdelku C zelo hitro oz. eksponentno. Realno, v praksi, seveda ni mogoče, da se rast proizvodnje slej ko prej ne bi končala oz. omejila. Proizvodnja ima svoje omejitve in ekonomske zakonitosti. Na tej točki učenci začutijo izziv, kako pojasniti dano situacijo, kako napovedovati ter kako razumeti matematični model $z$ vidika realistične situacije. Če učenci nimajo veliko ekonomskega znanja, se soočijo s situacijo, kako na čim ustvarjalnejši način raziskati dano situacijo z znanjem, ki ga imajo. 


\section{Oblikovanje problemov}

Tudi samostojno oblikovanje problemov je odprti problem, saj reševalcu dopušča izbiro. Pri primeru, ki ga predstavljamo v nadaljevanju, teče koncept reševanja nasprotno kot pri ustaljenih pristopih v praksi (primer 6). Dana je rešitev oz. strategija reševanja, potrebno je poiskati problem, rešljiv $z$ dano enačbo.

Iz problemov, ki jih učenci oblikujejo, lahko ocenimo raven njihovega (matematičnega) znanja, obseg besedišča, izvirnost v navajanju primerov idr., saj bodo navadno oblikovali probleme, ki jih lahko osebno rešijo. Učenci bodo v svoja pojasnila vključili svoje osebne zgodbe in izkušnje. Zahvaljujoč temu lahko tudi veliko izvemo o njihovih interesih in življenju zunaj učilnice .

Primer 6: Oblikuj realistični problem, katerega rešitev bo rešitev enačbe:

$\frac{2}{3} \pi 10^{2} \cdot v \mathrm{~cm}^{3}=1000 \mathrm{~cm}^{3}$.

$V$ takih in podobnih primerih gre za ubesedenje in prevajanje matematične situacije $v$ drug kontekst (npr. življenjski, strokovni, znanstveni) na čim inovativnejši način. Ob prevajanju enačbe $\frac{2}{3} \pi 10^{2} \cdot v \mathrm{~cm}^{3}=1000 \mathrm{~cm}^{3} v$ realistični kontekst gre za razmislek o pomenu spremenljivke $v$ v življenjski situaciji ter ubesedenje problema $z$ uporabo jezika in matematike. Enačba dopušča oblikovanje velikega števila različnih problemov. Kako inovativen bo posameznik pri oblikovanju problema, je odvisno od njegovega znanja matematike na eni strani ter od sposobnosti prevesti matematični model $v$ izvirno realistično situacijo na drugi. Za vse to potrebuje domišljijo, fleksibilnost $v$ iskanju primernih povezav med spremenljivkami v enačbi s primerno vrednostjo $v$ življenjskem kontekstu: npr. spremenljivka $v$ v enačbi je lahko višina valja, $1000 \mathrm{~cm}^{3} \mathrm{v}$ enačbi predstavlja 1 liter tekočine, $\pi 10^{2} \cdot v \mathrm{~cm}^{3}$ predstavlja prostornino valja s polmerom $10 \mathrm{~cm}$.

Primer realističnega problema, katerega rešitev je rešitev enačbe

$$
\frac{2}{3} \pi 10^{2} \cdot v \mathrm{~cm}^{3}=1000 \mathrm{~cm}^{3},
$$

je npr:: Maj je 1 I soka pretočil v posodo valjaste oblike $s$ polmerom $10 \mathrm{~cm}$ in jo napolnil do dveh tretjin. Kako visoka je valjasta posoda?

Lahko bi trdili, da so tovrstni pristopi dela pri matematiki še vedno premalo izkoriščeni tako $z$ vidika razvijanja jezikovne dimenzije pri matematiki kot tudi ustvarjalnosti.

\section{Algoritemsko reševanje problemov}

Po besedah Briggsove in Davisove (2008) ustvarjalnost v matematiki ne pomeni zgolj povsem nove rešitve problema, ustvarjalnost je tudi v izvirni poti 
reševanja. Četudi učenec še ne pozna zahtevnih matematičnih vsebin, pogosto lahko $s$ fleksibilno uporabo trenutnega znanja in s primerno izbiro strategije reševanja problem reši na svoj, inovativen način: s strategijo poskus napaka, $z$ analizo podatkov in odnosov med njimi, s prvinami algoritemskega mišljenja idr.

Pri predmetih, kot je matematika, pogosto uporabljamo algoritemsko razmišljanje, ne da bi se tega zares zavedali, npr. pri deljenju.

Algoritemsko razmišljanje nam omogoča, da razčlenimo probleme in konceptualiziramo rešitve $v$ smislu diskretnih korakov $v$ postopku (Wing 2006). Algoritemsko razmišljanje je povezano $z$ analitičnim mišljenjem, ki zahteva razstavljanje sporočila $v$ sestavne elemente ali dele na tak način, da so nam jasni odnosi in njihova organiziranost oz. relativna hierarhija. Analiza elementov vključuje urejanje podatkov po pomembnosti, razkrivanje skritih oz. zamegljenih podatkov, razčlenitev gradiva na sestavne dele, razlikovanje dejstev od hipotez, analiza odnosov pa pojasnjevanje osnovnih odnosov in razmerij med danimi elementi, prepoznavanje dejstev, ki so pomembna za formulacijo temeljne domneve in prepoznavanje vzročno-posledičnih odnosov.

Primer 7: Cestni ropar je videl, da ima Bogatin 100 zlatnikov, Bogatinka pa 200 zlatnikov, zato je Bogatinki vzel trikrat toliko zlatnikov kot Bogatinu. Po ropu je imel g. Bogatin dvakrat toliko zlatnikov kot Bogatinka. S koliko denarja je odšel ropar? (Povzeto po Mršnik in Novak 2016)

Četudi učenec še ne pozna linearne enačbe, lahko s primerno izbiro strategije reševanja problem reši na svoj, inovativen način.

Primer strategije reševanja z uporabo algoritemskega razmišljanja in sistematičnega zapisa.

Predstavljeni način reševanja lahko uporabijo učenci pred uvedbo linearne enačbe. $Z x(x \in \mathbb{N})$ označimo število zlatnikov, ki jih je ropar vzel Bogatinu. Ker gre za število zlatnikov, $x$ pripada množici naravnih števil $(x \in \mathbb{N})$. Strategija reševanja, ki jo prikazujemo v preglednici 4, je zastavljena po korakih ter temelji na poskušanju. Odločimo se za začetno vrednost spremenljivke $x$ in nadaljujemo v izbranem zaporedju.

Zadnji stolpec v preglednici pokaže na situacijo, ko je število zlatnikov, ki jih ima Bogatin, dvakrat tolikšno kot število zlatnikov, ki jih ima Bogatinka. Do rešitve smo prišli brez formalne uporabe enačbe. Za učenca, ki še ne pozna linearne enačbe oz. reševanja le-te, problem pa reši na način, da uporabi svoje trenutno znanje, je to lahko izkaz njegove ustvarjalnosti. 
Preglednica 4 Strategija reševanja problema: uporaba algoritmičnega razmišljanja in sistematičnega zapisa

\begin{tabular}{lrrrrrrr}
\hline & & $x=10$ & $x=20$ & $x=30$ & $x=40$ & $x=50$ & $x=60$ \\
\hline Bogatin & 100 & 90 & 80 & 70 & 60 & 50 & 40 \\
Bogatinka & 200 & 170 & 140 & 110 & 80 & 50 & 20 \\
Ropar & 0 & 40 & 80 & 120 & 160 & 200 & 240 \\
\hline & $90 \neq 2 \cdot 170$ & $80 \neq 2 \cdot 140$ & $70 \neq 2 \cdot 110$ & $60 \neq 2 \cdot 80$ & $50 \neq 2 \cdot 50$ & $40=2 \cdot 20$ \\
\hline
\end{tabular}

Strategija reševanja: reševanje z enačbo

S spremenljivko x označimo število zlatnikov, ki jih je cestni ropar vzel Bogatinu, in zapišemo enačbo.

$$
\begin{aligned}
100-x & =2(200-3 x) \\
x & =60
\end{aligned}
$$

Rešitev enačbe $x=60$ je število zlatnikov, ki jih je ropar vzel Bogatinu, torej je ropar skupno odšel z 240 zlatniki.

Ob zaključku reševanja naj učenci/dijaki predstavijo izbrano strategijo reševanja. V okviru evalvacije se lahko uporabi analiza SWOT, s katero tako učenci kot učitelj dobijo globlji uvid v izbrano strategijo reševanja ter (tudi ob spremljanju predstavitev ostalih vrstnikov) predvidijo tako možnosti izboljšav kot tudi kritične točke.

\section{Življenjski problem učenca}

Izziv Proračun gospodinjstva, ki ga navajamo v nadaljevanju, je primer iz vsakdanjega življenja učenca. Lahko bi ga navedli tudi kot primer medpredmetnega povezovanja oz. primer povezovanja matematike z okoljem in tudi kot primer s področja finančne pismenosti.

Primer 8: Proračun gospodinjstva. Imate $100 €$ tedenskega proračuna za vaše gospodinjstvo. Razmislite, kako boste porabili denar v naslednjem tednu in izdelajte tedenski proračun.

Z izzivom Proračun gospodinjstva raziskujemo, kako znamo ravnati z denarjem, ali znamo biti varčni oz. presoditi, čemu dati prednost, da bi čim racionalneje porabili denar. Poleg osnovnega znanja računanja se učenec sreča še z vrsto vprašanj, na katera mora odgovoriti: Kako načrtovati porabo denarja? Kaj je potrebno upoštevati pri izdelavi proračuna? Kako zbrati in urediti podatke?

Opredelimo vidike raziskovanja in oblikujemo preglednico $5, \mathrm{v}$ katero za vsak dan v tednu vpisujemo kupljene predmete oz. storitve, načrtovano in 
Preglednica 5 Proračun gospodinjstva

\begin{tabular}{lllllll}
\hline & $\begin{array}{l}\text { Izdelek/ } \\
\text { storitev }\end{array}$ & $\begin{array}{l}\text { Kupljeni } \\
\text { predmet }\end{array}$ & $\begin{array}{l}\text { Načrtovana } \\
\text { poraba } \\
\text { (NP) [€] }\end{array}$ & $\begin{array}{l}\text { Dejanska } \\
\text { poraba } \\
\text { (DP) [€] }\end{array}$ & $\begin{array}{l}\text { Razlika } \\
\text { med NP } \\
\text { in DP [€] }\end{array}$ & Stanje [€] \\
\hline Primer & & & 10 & 2 & 90 \\
\hline 12. 8. 2021 & $\begin{array}{l}\text { luksuzna } \\
\text { dobrina/ } \\
\text { potreba }\end{array}$ & Elektrika & 8 & & & \\
\hline Datum & $\begin{array}{l}\text { luksuzna } \\
\text { dobrina/ } \\
\text { potreba }\end{array}$ & & & & \\
& & & & & \\
\hline Izberi ključno vprašanje in opiši razmišljanje & & & \\
\hline Datum & $\begin{array}{l}\text { luksuzna } \\
\text { dobrina/ } \\
\text { potreba }\end{array}$ \\
\hline Izberi ključno vprašanje in opiši razmišljanje & & & \\
\hline
\end{tabular}

dejansko porabo denarja ter vsakodnevno stanje. Simulirajmo porabo tekom tedna.

Ob zaključku dejavnosti sledi elaboracija - predstavitev izdelave ideje, rezultatov ter evalvacija dejavnosti, pri kateri poskušamo odgovoriti na vprašanja: Smo porabili preveč? Zakaj? Kako bi denar lahko porabili drugače? Bi določene dneve lahko preživeli brez kakršnih koli izdatkov? Zakaj oz. zakaj ne? Ali so bili izdelki, ki smo jih kupili, luksuzna dobrina ali potreba? Pojasnimo, zakaj tako mislimo.

Pri evalvaciji je smiselno spodbuditi aktivno sodelovanje učencev $z$ medvrstniškim vrednotenjem in s podajanjem povratnih informacij $0 z . z$ drugimi prej naštetimi metodami, s katerimi hkrati razvijamo tudi ustvarjalnost.

\section{Zaključek}

Uvajanje ustvarjalnega učenja in poučevanja v pouk matematike ima lahko veliko prednosti tudi za razvoj in razumevanje matematičnega znanja kot tudi širše. Starbuck (2012) navaja, da ustvarjalno učenje in poučevanje učence navajata na ustvarjalno neodvisnost oz. samostojnost, ki je ključ do uspešnega samostojnega učenja. Podobno tudi Pečjak (1987), ki navaja, da je ustvarjalno delo svobodno in hkrati prinaša zadovoljstvo, ki je posledica notranje motivacije.

Učinkovito spodbujanje ustvarjalnosti zahteva tudi prilagojene pristope učenja in poučevanja. Zato je pomembno, da učitelj ustvarjalno mišljenje v prvi vrsti razvija pri sebi, da ga bo lahko spodbujal tudi pri učencih. Odkriva- 
nje neznanih razmerij, prepoznavanje in reorganizacija struktur v matematiki so $v$ šolah in razredih mogoči le s pomočjo usposobljenih učiteljev. Ti lahko pomagajo spodbujati ustvarjalno reševanje in oblikovanje problemov ter $\mathrm{s}$ tem usposabljati matematično ustvarjalne posameznike za prihodnost.

\section{Zahvala}

Članek je nastal v okviru projektnih dejavnosti nacionalnega projekta NA-MA POTI - Naravoslovna in matematična pismenost: spodbujanje kritičnega mišljenja in reševanje problemov ter učinkovita uporaba IKT. Naložbo sofinancirata Republika Slovenija in Evropska unija v okviru Evropskega socialnega sklada v okviru Operativnega programa za izvajanje evropske kohezijske politike v obdobju 2016-2022.

\section{Literatura}

Akgul, S., in N. G. Kahveci. 2016. »A Study on the Development of a Mathematics Creativity Scale.« Eurasian Journal of Educational Research 62:57-76.

Baran, G., S. Erdogan in A. Çakmak. 2011. »A Study on the Relationship between Sixyear-Old Children's Creativity and Mathematical Ability." International Education Studies 4 (1): 105-111.

Barwell, R. 2011. »Word Problems: Connecting Language, Mathematics and Life.« What Works? Research into Practice 34. http://www.edu.gov.on.ca/ eng/literacynumeracy/inspire/research/WW_Word_Problems.pdf.

Boaler, J., in C. S. Dweck. 2016. Mathematical Mindsets. San Francisco, CA: JosseyBass.

Brečko, D. 2002. Štirideset sodobnih učnih metod. Ljubljana: Sofos.

Briggs, M., in S. Davis. 2008. Creative Teaching: Mathematics in the Early Years and Primary Classroom. London: Routledge.

Chamberlin, S. A., in E. L. Mann. 2014. »A New Model of Creativity in Mathematical Problem Solving. "V Proceedings of the 8th Conference of MCG International Group for Mathematical Creativity and Giftedness, 35-40. Denver, CO: University of Denver, International Group for Mathematical Creativity and Giftedness.

De Bono, E. 2009. Naučite svojega otroka misliti. Prev. M. Domjan Cerar. Maribor: Rotis.

De Corte, E. 2010. »Historical Developments in the Understanding of Learning." $V$ The Nature of Learning, Using Research to Inspire Practice, ur. H. Dumont, D. Istance in F. Benavides, 35-67. Pariz: OECD.

Glogovec, Z., in D. Žagar. 1992. Ustvarjalnost: projektno vzgojno delo. Ljubljana: Zavod Republike Slovenije za šolstvo in šport.

Hoffman, L. R., in D. J. Brahier. 2008. »Improving the Planning and Teaching of Mathematics by Reflecting on Research." Mathematics Teaching in the Middle School 13 (7): 412-417. 
Imai, T. 2010. »The Influence of Overcoming Fixation in Mathematics towards Divergent Thinking in Open-Ended Mathematics Problems on Japanese Junior High School Students. International Journal of Mathematical Education in Science and Technology 31 (2): 187-193.

Jurčová, M. 2005. »Creativity Research at the Institute of Experimental Psychology SASc - Areas, Topics, Methods and Findings." Studia Psychologica 47 (4): 263-276.

Kim, H., S. Cho in D. Ahn. 2003. »Development of Mathematical Creative Problem Solving Ability Test for Identification of Gifted in Math.« Gifted Education International 18 (2): 164-174.

Kirby, D. A. 2003. Entrepreneurship. London: McGraw-Hill Higher Education.

Krutetskii, V. A. 1976. The Psychology of Mathematical Abilities in School Children. Chicago, IL: University of Chicago Press.

Leikin, R., in M. Lev. 2007. »Multiple Solution Tasks as a Magnifying Glass for Observation of Mathematical Creativity. « V Proceedings of the 31st International Conference for the Psychology of Mathematics Education, ur. J. H. Woo, H. C. Lew, K. S. Park in D. Y. Seo, 161-168. Seul: The Korea Society of Educational Studies in Mathematics.

Maharani, H. R. 2014. "Creative Thinking in Mathematics: Are We Able to Solve Mathematical Problems in a Variety of Way?« V ICMSE 2014: International Conference on Mathematics, Science, and Education, 120-125. Semarang City: Faculty of Mathematics and Natural Sciences Semarang State University.

Mann, E. L. 2005. »Mathematical Creativity and School Mathematics: Indicators of Mathematical Creativity in Middle School Students. « Doktorska disertacija, University of Connectitut.

Marentič Požarnik, B. 2003. Psihologija učenja in pouka. Ljubljana: DZS.

McGregor, D. 2007. Developing Thinking, Developing Learning. New York: McGraw-Hill Education.

Ministrstvo za šolstvo in šport. 2011. Učni načrt:program osnovna šola; matematika. Ljubljana: Ministrstvo za šolstvo in šport in Zavod Republike Slovenije za šolstvo.

Mršnik, S., in L. Novak. 2016. »Ustvarjalnost in reševanje problemov na razredni stopnji.«Prispevek predstavljen na KUPM 2016: 3. mednarodni konferenci o učenju in poučevanju matematike, Kranj, Slovenija, 16.-17. november. https://www.zrss.si/kupm2016/wp-content/uploads/mrsnik_novak _kupm_2016.pdf.

Munandar, S. C. U. 2002. Creativity and Giftedness Strategy Delivering Creative Potential and Talent. Jakarta: Granada Pustaka Utama.

Pavlič Škerjanc, K. 2013. »Jezikovno obogateni kurikul: krosukurikularna vloga tujih jezikov. Jezikovne povezave 2: razvijanje strokovne(-ih) pismenosti v TJ (NEM).«Projekt Obogateno učenje tujih jezikov II, Program profesional- 
nega usposabljanja učiteljev. https://www.zrss.si/projektiess/skladisce/ outj2/04_USPOSABLJANJA/13-05-14_ZRS\%C5\%Ao(NJD)/Gradiva\%20ZRS \%C5\%Ao/13-05-14_zrs\%C5\%A1-4_strokpismenost(njd).pdf.

Pečjak, V. 1987. Misliti, delati in živeti ustvarjalno. Ljubljana: DZS.

Petač, D. 2011. »Razvijanje ustvarjalnih sposobnosti učencev v prvem triletju 9letne osnovne šole: diplomsko delo. "Diplomsko delo, Univerza v Ljubljani.

Pogačnik, V. 1995. Pojmovanje inteligentnosti. Radovljica: Didakta.

Ruseffendi, E. T. 2006. Introduction to Helping Teachers Develop Competence in Teaching Math To Improve CBSA. Bandung: Tarsito.

Rutar Ilc, Z., in K. Pavlič Škerjanc. 2010. Medpredmetne in kurikularne povezave: priročnik za učitelje. Ljubljana: Zavod Republike Slovenije za šolstvo.

Silver, E. A. 1997. »Fostering Creativity through Instruction Rich in Mathematical Problem Solving and Thinking in Problem Posing.« ZDM-The International Reviews on Mathematical Education 29 (3): 75-80.

Siswono, T. Y. E. 2008. »Promoting Creativity in Learning Mathematics Using Open-Ended Problems.« Prispevek predstavljen na The 3rd International Conference on Mathematics and Statistics (ICoMS-3), Bogor, Indonezija, 5.6. avgust.

- 2011. »Level of Student's Creative Thinking in Classroom Mathematics." Educational Research and Reviews 6 (7): 548-553.

Sriraman, B. 2004. »The Characteristics of Mathematical Creativity.« Mathematics Educator 14 (1): 19-34.

Sriraman, B., in P. Haavold. 2017. „Creativity and Giftedness in Mathematics Education: A Pragmatic View. "V Compendium for Research in Mathematics Education, ur. J. Cai, 908-916. Reston, VA: National Council of Teachers of Mathematics.

Starbuck, D. 2012. Creative Teaching: Learning with Style. New York: Bloomsbury.

Strmčnik, F. 2003. »Didaktične paradigme, koncepti in strategije.« Sodobna pedagogika 54 (1): 80-92.

Valenčič Zuljan, M., in J. Kalin. 2020. Učne metode in razvoj učiteljeve metodične kompetence. Ljubljana: Pedagoška fakulteta.

Wing, J. M. 2006. »Computational Thinking."Communications of the ACM 49 (3): 33-35.

Woolfolk, A. 2002. Pedagoška psihologija. Prev. M. Hudoklin. Ljubljana: Educy.

\section{Maths in Real Life: Creative Solving of Authentic Problems}

Creativity is an important part of our daily lives and also an important factor in encouraging innovation and creating new ideas, which is crucial for individuals' sustainable development. How this is reflected depends on our personality, temperament, strengths, and the environment in which we live and operate. Many authors agree that creative thinking is thinking that leads to 
new insights, new approaches, new perspectives, and new ways of understanding things, and expose creative thinking as a dynamic mental process that includes divergent and convergent thinking. In this paper, we present the criteria and conditions necessary for creativity in mathematics and the connection of mathematics with the environment, where we analyse four components of creative thinking on the examples of authentic problems: fluency, flexibility, originality and elaboration. Through solving realistic and mathematical problems, we elaborate the ways of creative thinking, inter alia in solving open problems, algorithmic problem solving, creating original questions, etc. In selected examples, we indicate the possibilities of connecting and increasing complexity vertically from primary to secondary school.

Keywords: creativity, innovation, mathematics, authentic problems, creative thinking 